\title{
Undergraduate students' perceptions of factors affecting job satisfaction
}

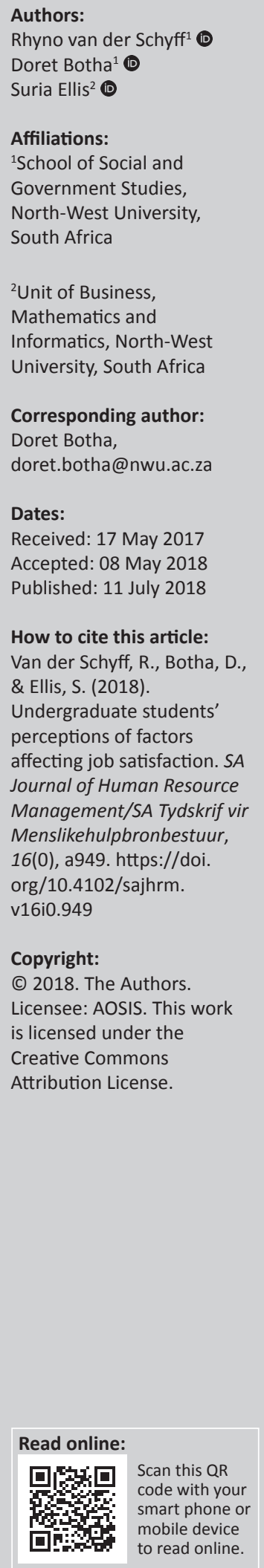

Orientation: Globally, people engage in work and sell their services to an organisation in exchange for compensation. This compensation can have a significant effect on employees' attitude towards their work, resulting in either job satisfaction or job dissatisfaction. A high level of job satisfaction can increase organisational effectiveness and, subsequently, the organisation's performance, whereas job dissatisfaction can cause employees to be less motivated, which can in turn decrease their productivity, effectiveness and individual performance.

Research purpose: This study was conducted with the aim to investigate undergraduate students' perceptions of the factors affecting job satisfaction.

Motivation for the study: Currently, there is a paucity of published research on the views of undergraduate students on the factors affecting job satisfaction.

Research approach/design and method: The study took a positivistic research approach, and a quantitative design was used. A stratified quota sampling technique was employed to select the respondents for the study; a certain quota was met in terms of race, gender and faculty of study. In total, 270 undergraduate students participated in the study.

Main findings: The empirical results indicated no significant association between the demographic variables (previous work experience, gender, race and field of study) and almost all occupational dimensions of job satisfaction, working conditions and recognition. However, medium to large positive relations were measured between the dimensions of job satisfaction, working conditions and recognition. It was evident from the study that all the dimensions measured are considered important for obtaining job satisfaction in the workplace.

Practical and managerial implications: It is important for managers to get an understanding of the views of young people on work-related issues in order to create an understanding of young people's needs and aspirations, as they are the future permanent labour force, managers and leaders of a country.

Contribution/value-add: The study brought to light the views of undergraduate students on the factors affecting job satisfaction.

\section{Introduction}

Globally, people engage in work to receive rewards that help satisfy their needs. Therefore, employees 'sell' their services to an organisation in exchange for compensation (Jiang, Xiao, Qi, \& Xiao, 2009). Compensation includes a cash component (salary, merit increases, bonuses, stock options and other incentives) and benefits (e.g. health and unemployment insurance) (Noe, Hollenbeck, Gerhart, \& Wright, 2012). This compensation can have a significant effect on employees' attitude towards their work, influencing individuals to be satisfied or dissatisfied with their jobs (Milkovich, Newman, \& Gerhart, 2011).

Job satisfaction refers to employees' subjective attitude towards their job (Aziri, 2011; Gazioglu \& Tansel, 2006; Nel et al., 2014). It is regarded as the emotional reaction an individual experiences through comparing the desired outcomes with the actual outcomes (Rothman, 2001). Therefore, 'job satisfaction describes a positive feeling about a job, resulting from an evaluation of its characteristics' (Robbins, Judge, Odendaal, \& Roodt, 2009, p. 74).

There are certain factors that can influence individuals' behaviours and attitudes towards their job, which can subsequently result in either job satisfaction or job dissatisfaction (Malik, Nawab, Naeem, \& Danish, 2010). These factors include, among others, salary, promotion, workload, 
working conditions, the nature of the work and motivation (Hayes, Bonner, \& Pryor, 2010; Lumley, Coetzee, Tladinyane, \& Ferreira, 2011). If employees are satisfied with most of the factors they consider relevant, job satisfaction will be experienced (Werner, Bagraim, Cunningham, Potgieter, \& Viedge, 2016).

Job satisfaction is important for both organisations and the individual (Moynihan \& Pandey, 2007). A high level of job satisfaction can increase organisational effectiveness and, subsequently, the organisation's performance, whereas job dissatisfaction can cause employees to be less motivated, which can in turn decrease their productivity, effectiveness and individual performance (Alam \& Mohammad, 2010; Aziri, 2011; Moynihan \& Pandey, 2007). Meyer et al. (2012, p. 99) postulate that 'in most South African companies there is a lack of job satisfaction', resulting in 'a low level of employee commitment to performance and the achievement of organisational goals' with the following symptoms: 'low productivity, high absenteeism, labour unrest, industrial action and high labour turnover'.

The exit-voice-loyalty-neglect framework indicates the consequences of job dissatisfaction (Robbins et al., 2009). The framework indicates four ways in which an individual may react towards job dissatisfaction. Firstly, an individual might feel the need to leave the organisation, which may include looking for a new position as well as resigning (exit response). Secondly, an individual might try to actively and constructively improve conditions by engaging with the organisation (voice response). Thirdly, an individual might passively and optimistically wait for conditions to improve without seeking a new position (loyalty response). Lastly, an individual might begin to passively and destructively allow conditions to worsen, including chronic absenteeism or lateness, reduced effort and an increase in mistakes in work tasks (neglect response) (Robbins et al., 2009; Werner et al., 2016).

This study was conducted with the aim to investigate undergraduate students' perceptions of the factors affecting job satisfaction, as they will soon enter the working environment on a more permanent basis. Currently, there is a paucity of published research on the views of undergraduate students on work-related issues, such as factors affecting job satisfaction. The research study supplies managers with a perspective from students who are yet to enter a working environment. A recent research study conducted by Jiang and Alexakis (2017) comparing students' and managers' perceptions of essential entry-level management competencies revealed that managers and students have different perceptions regarding entry-level management competencies. It is subsequently important for managers to get an understanding of the views of young people on work-related issues in order to create an understanding of young people's needs and aspirations, as they will be future employees. The results of this research study provide managers with the necessary information regarding undergraduate students' expectations of the required entry-level managerial competencies.

\section{Purpose}

The purpose of the study on which this article reports was to determine the extent to which perceptions of occupational dimensions influence undergraduate students' perceptions of job satisfaction.

\section{Literature review}

The literature review discusses theoretical explanations of job satisfaction as well as variables (occupational dimensions) of job satisfaction.

\section{Theoretical explanations of job satisfaction}

There are strong overlapping characteristics between theories relating to job satisfaction and theories relating to human motivation, as both focus on the movement of workers to act in a desired manner (Tietjen \& Meyers, 1998, as cited in De Jager, 2015). Employee motivational factors can be divided into extrinsic and intrinsic factors. The content of an individual's job, such as the individual's responsibilities, free will or autonomy, skills and supervision, relates to the individual's intrinsic satisfaction and encompasses the qualitative attributes of an individual's job (Rose, 2001, as cited in Chatzoglou, Vraimaki, Komsiou, Polychrou, \& Diamantidis, 2011). On the other hand, the individual's working environment is concomitant to extrinsic satisfaction and includes the individual's working hours, opportunities for promotion, safety, rewards and bonuses, among others (Rose, 2001, as cited in Chatzoglou et al., 2011). Goetz et al. (2012) depict job satisfaction as the extent to which individuals' intrinsic and extrinsic aspects of their job influence them to feel negative or positive towards their job, subsequently describing the attitudes that individuals have towards their jobs. The following theories attempt to explain job satisfaction: Maslow's hierarchy of needs theory, Herzberg's motivation hygiene theory, McClelland's acquired needs theory, Alderfer's existence, relatedness and growth (ERG) theory, Locke's value-percept theory and the job characteristics model. This study aimed to explore the undergraduate students' perceptions of occupational dimensions and job satisfaction, and therefore the following theories are discussed as they informed the development of the measuring instrument used: Maslow's hierarchy of needs theory, Herzberg's motivation hygiene theory and Alderfer's ERG theory.

\section{Maslow's hierarchy of needs theory}

Theories that attempted to explain the concept of job satisfaction began with Maslow's hierarchy of needs theory in 1943 (De Jager, 2015). Abraham H. Maslow, a clinical psychologist, developed this theory after years of observing his patients (Werner et al., 2016). Maslow argued that human beings have several needs, which can be categorised in a hierarchy based on importance for survival. The author divided human needs into five main categories. The lowest level contains the most basic needs that must be met before higher order needs emerge and become important to the individual (Nel et al., 2014). Maslow's hierarchy of needs includes the following: psychological needs (lowest order needs), safety needs (second level of needs), social needs 
(third level of needs), esteem needs (fourth level of needs) and self-actualisation needs (highest level of needs; the need for self-fulfilment) (Werner et al., 2016).

\section{Herzberg's motivation hygiene theory}

Frederick Herzberg modified Maslow's hierarchy of needs theory and developed the dual-structure theory, also known as the two-factor motivation theory, in 1959 (De Jager, 2015). Herzberg identified two sets of factors that influence motivation and job satisfaction, namely hygiene factors and motivators (Nel et al., 2014). Hygiene factors are related to the working environment and include organisational policy and administration; equipment; supervision; interpersonal relationships with colleagues, superiors and subordinates; salary; status; working conditions; and work security. On the other hand, motivational factors (or motivators) include achievement, recognition, the job itself (how meaningful, interesting and challenging it is), progress or growth (learning and developing), responsibility and feedback (Nel et al., 2014).

Hygiene factors aim to prevent an individual's bad feelings, or job dissatisfaction, but do not necessarily lead to job satisfaction, whereas motivation factors aim to achieve job satisfaction (Dartey-Baah \& Amoako, 2011; Tan \& Waheed, 2011). Herzberg's theory argues that an individual is more likely to experience job satisfaction in a working environment with a high level of hygiene and motivational factors (DarteyBaah \& Amoako, 2011; Malik, 2011; Watson, 2012).

Herzberg's theory can be linked to Maslow's hierarchy of needs theory. Hygiene factors relate to the lower level needs in the hierarchy and motivational factors to the higher level needs (Nel et al., 2014).

\section{Alderfer's existence, relatedness and growth theory}

Clayton Alderfer's ERG theory, developed in 1972, is closely related to Maslow's hierarchy of needs theory (Grobler, Wärnich, Carrell, Elbert, \& Hatfield, 2011; Werner et al., 2016). The E, R and G refer to three basic human need categories, namely, existence needs, relatedness needs and growth needs. Existence needs refer to a person's physical and material needs and are similar to the physiological and safety needs (first and second level of needs) in Maslow's hierarchy. Relatedness needs are equivalent to Maslow's social needs (third level of needs). Growth needs refer to the individual's desire to be productive and creative and are parallel to Maslow's needs for self-esteem and self-actualisation (higher level needs) (Werner et al., 2016).

Alderfer described two forms of movement through his hierarchy: satisfaction-progression (movement up the hierarchy) and frustration-regression (movement down the hierarchy). The satisfaction-progression movement relates to Maslow's theory. The frustration-regression movement describes what happens when a person's need is frustrated at the higher level. This may lead to movement down the hierarchy as a person's satisfaction at the next level is frustrated (Werner et al., 2016).

\section{Variables of job satisfaction}

In the past, numerous researchers examined different demographic and work-related variables in an attempt to explain levels of job satisfaction.

\section{Demographic variables}

Demographics of employees are strong determinants of the level of job satisfaction (Al-Zoubi, 2012). For this particular study, gender, race, field of study and previous work experience were measured and are discussed.

Gender differences in job satisfaction have been reported in various studies (Gazioglu \& Tansel, 2006; Hersch \& Xiao, 2016; Moyes, Shao, \& Newsome, 2008; Sabharwal \& Corley, 2009). The literature suggests that women are more satisfied than men with their jobs (Gazioglu \& Tansel, 2006; Hersch \& Xiao, 2016), despite still being subjected to discriminatory practices in the workplace such as lower pay and fewer opportunities for advancement. Some possible explanations for this tendency include gender differences in values, job expectations and labour force participation rates (Hersch \& Xiao, 2016). Moyes et al. (2008) emphasise the impact of gender differences on employment values and assert that women value the intrinsic attributes of the job more, including the social and emotional aspects of place of employment, positive relations with peers and job contentment. In contrast, men value the extrinsic attributes of the job more, such as high salaries, opportunities for advancement, job security and work independence (Moyes et al., 2008). This view is also confirmed by Sabharwal and Corley (2009). Abu-Saad and Isralowitz (1997) argue that women are traditionally socialised to be less occupation-orientated, but that female students who identify less with traditional gender values tend to be more orientated towards occupational environments. Abu-Saad and Isralowitz (1997) conducted research focusing on the influence of gender on work values among undergraduate students. The authors did not discover any consistent patterns regarding gender differences in terms of perceptions of job satisfaction. They did, however, discover that married male students are significantly more career-orientated than married female students (Abu-Saad \& Isralowitz, 1997).

Stoermer, Hitotsuyanagi-Hansel and Froese (2017) highlight the importance of focusing on the relationship between race and job satisfaction in order to maximise the efficiency of an organisation. According to Stoermer et al. (2017), various previous studies focused on the relationship between race and job satisfaction, where these studies reported mixed, and sometimes contradictory, results. Hersch and Xiao (2016) found that black and Asian workers experience lower levels of job satisfaction than white workers; however, little inquiry has been launched into this racial differentiation. Contradictory findings were reported by Friday and Friday (2003, as cited in Stoermer et al., 2017), indicating that higher levels of job satisfaction were reported by black employees. Stoermer et al. (2017) found that black employees experience indefinite amounts of racial discrimination in the South African context, 
which in turn results in the experience of job dissatisfaction. Hoppe, Fujishiro and Heaney (2014) indicate that, as minority groups, racial identities such as black and Hispanic identities experience increasing levels of job satisfaction if they have the same racial co-workers. Koh, Shen and Lee (2016) indicate the differences between white and black individual job satisfaction as higher than the difference between white and other racial experiences of job satisfaction. Josiam et al. (2009) conducted a study that focused on the work attitudes of Generation Y students, as the perceptions of students before they experience the working environment can influence how they experience the working environment. The authors found that there are no significant racial differences in the perceptions of these students, although these findings are based on the context of developed countries (Josiam et al., 2009).

$\mathrm{Wu}$ and Norman (2006) identified a relationship between students' field of study and job satisfaction and reported that undergraduate nursing students fear the nursing environment as a result of its high turnover rates, which can subsequently lead to job dissatisfaction. West et al. (2014) indicate that medical interns report high levels of job dissatisfaction. Liu (2017) indicates that higher levels of job satisfaction are experienced by accounting interns. A research study focusing on psychology undergraduate students and work variables conducted by Levin and Stokes (1989) indicated that negative affectivity, such as a poor self-esteem and negative emotions, can negatively influence perceptions of the working environment and overall satisfaction.

Various authors identified a relationship between previous work experience and job satisfaction (Chang, Ma, Chiu, Lin, \& Lee, 2009; Kardam \& Rangnekar, 2012). Literature suggests that individuals with previous work experience have higher levels of job satisfaction because they have already experienced the difficulty of shifting jobs (Kardam \& Rangnekar, 2012). Elfering, Odoni and Meier (2016) indicate that the relationship between previous work experience and the level of job satisfaction experienced by employees is largely maintained by the emotional experiences attached to the previous working environment. Resick, Baltes and Shantz (2007) conducted research on work decisions and attitudes. The authors found that previous work experience influences preconceived ideas about the working environment and working expectations. These ideas or perceptions might be different from the reality of the next working environment students enter and might subsequently lead to lower levels of satisfaction (Resick et al., 2007).

\section{Work-related variables}

Work-related variables relate to the work itself and its attributes (Chatzoglou et al., 2011) and also include the characteristics of work that result in intrinsic and/or extrinsic satisfaction.

According to Grobler et al. (2011), the most important factors (most surveyed employees reported) contributing to job satisfaction are regarded as the following:
- the job itself, including the kind of work employees perform (challenging or interesting) and the freedom allowed in terms of how the work is performed (Gazioglu \& Tansel, 2006; Millán, Hessels, Thurik, \& Aguado, 2013; Shin \& Jung, 2014; Skaalvik \& Skaalvik, 2014)

- quality co-worker relations, including the extent to which an individual is accepted as part of a work unit as well as the friendliness and support of fellow colleagues (Millán et al., 2013; Pan, 2015; Smith, 2015; Tang, Siu, \& Cheung, 2014)

- good supervision, including aspects such as fairness, helpfulness, competency and effectiveness (Fu \& Deshpande, 2014; Pan, 2015; Smith, 2015)

- opportunity to grow, which includes advancement opportunities (Hanna, Kee, \& Robertson, 2017; Hartman, Rutherford, Feinberg, \& Anderson, 2014; Proudfoot \& Lind, 2015; Smith, 2015).

Grobler et al. (2011) further assert that the most frequently reported factors that diminish job satisfaction are the following:

- poor supervisory practices, such as unfair, biased treatment, failure to listen and respond to employees' concerns and problems with management's communication credibility (Fu \& Deshpande, 2014; Mathieu, Neumann, Hare, \& Babiak, 2014; Pan, 2015)

- interpersonal conflict, including lack of teamwork, unfriendly colleagues and rivalry among managers and supervisors (Pan, 2015; Smith, 2015; Tang et al., 2014)

- poor working environment, involving dirty, noisy, unsafe and unhealthy working conditions (Dul, Ceylan, \& Jaspers, 2011; Valentine, Godkin, Fleischman, \& Kidwell, 2011)

- low, uncompetitive pay (Chowdhary, 2013; Ingram, 2015; Judge, Weiss, Kammeyer-Mueller, \& Hulin, 2017).

\section{Research methodology Research approach}

This study took a positivistic research approach. Positivist research aims to explore, explain, evaluate, predict and develop or test theories (Sarantakos, 2013). A quantitative design was used, which supplied the study with direction as well as certain procedures (Creswell, 2009). A quantitative study applies attention to gaining knowledge objectively and systematically through deductive reasoning and generalisation (Sousa, Driessnack, \& Mendes, 2007). The research aimed to retrieve information concerning undergraduate students' perceptions of occupational dimensions and job satisfaction and quantified these results through the use of numbers (see O'Leary, 2013).

\section{Population and sample}

The population used for this study consisted of undergraduate students of one of the campuses of a South African university. The study employed a stratified quota sampling technique; respondents were randomly selected from the population. The sample consisted of 270 undergraduate students based on the campus. A certain quota was met in terms of race, gender and faculty of study. Table 1 presents the survey population frame. 


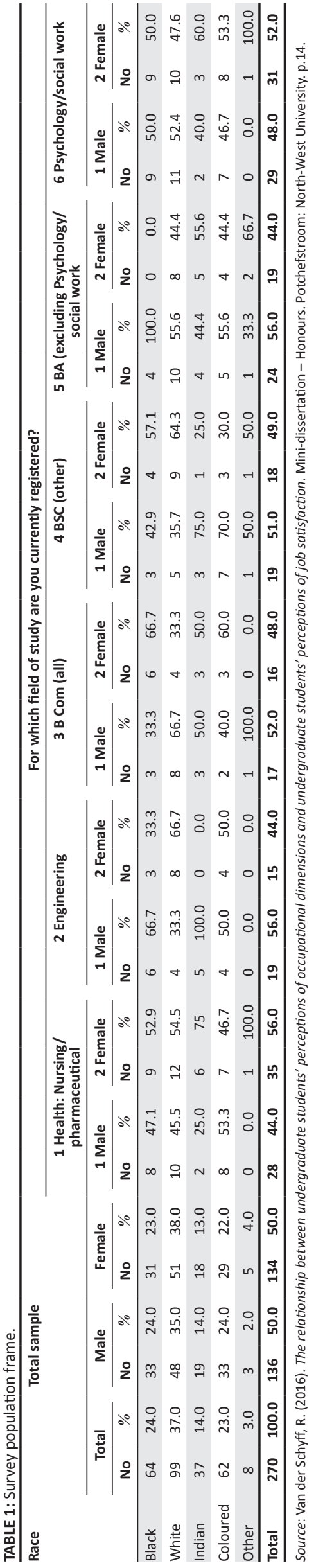

The sample was equally divided between the gender groups (50\% male and 50\% female respondents). Furthermore, it consisted of $23.3 \%$ nursing or pharmaceutical students, $12.6 \%$ engineering students, $12.2 \%$ economic and management sciences students, $13.7 \%$ natural sciences students, $15.9 \%$ human and social sciences students and $22.2 \%$ psychology or social work students. It was also evident from the sample that the majority of the students (57\%) were exposed to working environments of some kind (permanent, full-time, casual, clerical, technical, voluntary and pharmacy assistance).

\section{Data collection strategy}

Data were collected through face-to-face surveys, using a self-constructed coded questionnaire that consisted of a 5-point Likert-type scale, ranging from very strongly disagree (1) to very strongly agree (5). Administering a questionnaire has several advantages, including the following: higher response rates can be attained, the number of 'do not knows' and 'no answers' is generally decreased and the interviewer can clarify misunderstanding of the intent of the questions, thereby ensuring relevant responses (Babbie \& Mouton, 2009).

\section{Analysis and reporting}

The data gathered were processed with the Statistical Package for the Social Sciences (SPSS Version 24). A factor analysis was conducted to explore the underlying structure of job satisfaction, working conditions and recognition. Cronbach's alpha coefficient was used to determine internal reliability. Furthermore, descriptive statistics, correlations, $t$-tests and ANOVAs were used to analyse the data. Cohen's $d$-values were used as effect size to determine whether differences in means were important in practice, where $d=0.2$ were considered as small, $d=0.5$ as medium and $d=0.8$ as large effects (Cohen, 1988). Cohen (1988) suggested that correlations of $0.1,0.3$ and 0.5 can be interpreted as small, medium and large correlations, respectively.

\section{Limitations of the research design}

The study focused on undergraduate students studying on one campus of a South African university, excluding the other two campuses. Subsequently, the results of the study cannot be generalised to all undergraduate students of the university. Furthermore, not all students were exposed to real working environments and this may also have influenced the results.

\section{Ethical consideration}

This research study was formally approved by the Ethics Committee of the Faculty of Arts of one of the campuses of a South African university. The researchers also adhered to the correct ethical standards. The researchers scheduled appointments with the sampled respondents in their free time. The face-to-face interviews were administered, privately, in specific offices of the university allocated to the researchers. 
Each respondent signed an informed consent form permitting the researcher to include them in the research. The informed consent form clarified the purpose of the study as well as the nature of the research and ensured the privacy, anonymity and confidentiality of the respondents. No student was forced to participate in the study and they were informed that they could withdraw from the study at any time. It is of extreme importance to protect respondents from any harm, be it physical, cognitive or emotional (Ritchie, Lewis, Nicholls, \& Ormston, 2013); these ethical considerations were also taken into account while conducting the research.

\section{Empirical results}

This section provides the empirical results of the research.

\section{Validity and reliability}

\section{Job satisfaction}

An exploratory factor analysis was conducted on the 26 selfconstructed Likert-type scale items measuring perceptions of job satisfaction. Principal component analysis and oblimin rotation were used. This was meant to determine the dimensionality of the job satisfaction instrument used. The Kaiser-Meyer-Olkin test (KMO) measured 0.93 and indicated that the sample size was adequate for factor analysis. The $p$-value of Bartlett's test of sphericity returned a value smaller than 0.05 , suggesting that the correlation between statements was sufficient for factor analysis (see Field, 2005). Five factors (management and leadership needs, wellness, emotional needs, advancement and dignity) were extracted through Kaiser's criteria (see Field, 2005) that explain $60.67 \%$ of the total variance. The factor loadings of the management and leadership needs factor ranged from 0.457 to 0.903 , the wellness factor from 0.531 to 0.825 , the emotional needs factor from 0.401 to 0.798 and the advancement factor from 0.576 to 0.821 . Only one question loaded on the dignity factor with a factor loading of 0.814 .

The Cronbach's alpha coefficient for the management and leadership needs and emotional needs factors calculated 0.92 and 0.84 , respectively, which is well above the required 0.70 , and show high reliability and internal consistency. The wellness factor showed a Cronbach's alpha coefficient of 0.62 , which could be regarded as an acceptable reliability. The advancement factor had a Cronbach's alpha coefficient of 0.51 , which could be regarded as a relatively low reliability. This was caused by the low number of statements, namely two in the factor. The mean inter-item correlation was 0.382 , which is sufficient according to Clark and Watson (1995). Only one item loaded on the dignity factor, therefore Cronbach's alpha was not applicable.

The means scores of all five factors were four and above, indicating that on average the respondents held the opinion that the items contained in the five factors will be regarded as factors that will contribute to students' job satisfaction in their future working environments. The following response categories were used: 1 = very strongly disagree; 2 = fairly strongly disagree; $3=$ agree; 4 = fairly strongly agree and $5=$ very strongly agree.

\section{Working conditions}

A factor analysis was conducted on the nine self-constructed Likert-type scale items measuring perceptions of working conditions. Principal component analysis and oblimin rotation were used. The KMO measured 0.86 , indicating that the sample size was adequate for factor analysis. The $p$-value of Bartlett's test of sphericity returned a value smaller than 0.05 , suggesting that the correlation between statements was sufficient for factor analysis (see Field, 2005). Only one factor (working conditions) was extracted through Kaiser's criteria (see Field, 2005) that explains $55.86 \%$ of the total variance. The factor loading ranged from 0.671 to 0.828 .

The Cronbach's alpha coefficient of the working conditions factor was 0.90 , indicating high reliability and internal consistency. The factor mean was 4.55 , indicating that a large majority of respondents thought that the items contained in the factor are regarded as aspects contributing to appropriate working conditions. The following response categories were used: 1 = very strongly disagree; 2 = fairly strongly disagree; 3 = agree; 4 = fairly strongly agree and 5 = very strongly agree.

\section{Recognition}

A factor analysis was conducted on the six self-constructed Likert-type scale items measuring underlying dimensions of perceptions of appropriate working conditions. Principal component analysis and oblimin rotation were used. The KMO measured 0.80, which indicated that the sample size was adequate for factor analysis. The $p$-value of Bartlett's test of sphericity returned a value smaller than 0.05 , suggesting that the correlation between statements was sufficient for factor analysis (see Field, 2005). Two factors (extrinsic rewards and intrinsic rewards) were extracted through Kaiser's criteria (see Field, 2005) that explain $73.49 \%$ of the total variance. The factor loadings of the extrinsic rewards factor ranged from 0.736 to 0.941 and the intrinsic rewards factor from 0.782 to 0.855 .

The Cronbach's alpha coefficient of the extrinsic and intrinsic rewards factors were 0.86 and 0.75 , respectively, indicating high reliability and internal consistency. The mean scores were 4.16 for extrinsic rewards and 3.96 for intrinsic rewards, indicating that a large majority of respondents held the opinion that the items contained in the factors are regarded as factors contributing to recognition. However, on average, the respondents were in higher agreement with extrinsic rewards than intrinsic rewards. The following response categories were used: 1 = very strongly disagree; 2 = fairly strongly disagree; 3 = agree; $4=$ fairly strongly agree and 5 = very strongly agree.

\section{Correlations between job satisfaction, working conditions and recognition}

The correlations between job satisfaction, working conditions and recognition are reflected in Table 2. Medium to large positive correlations between 0.30 and 0.77 were found between the five dimensions of job satisfaction. Working 


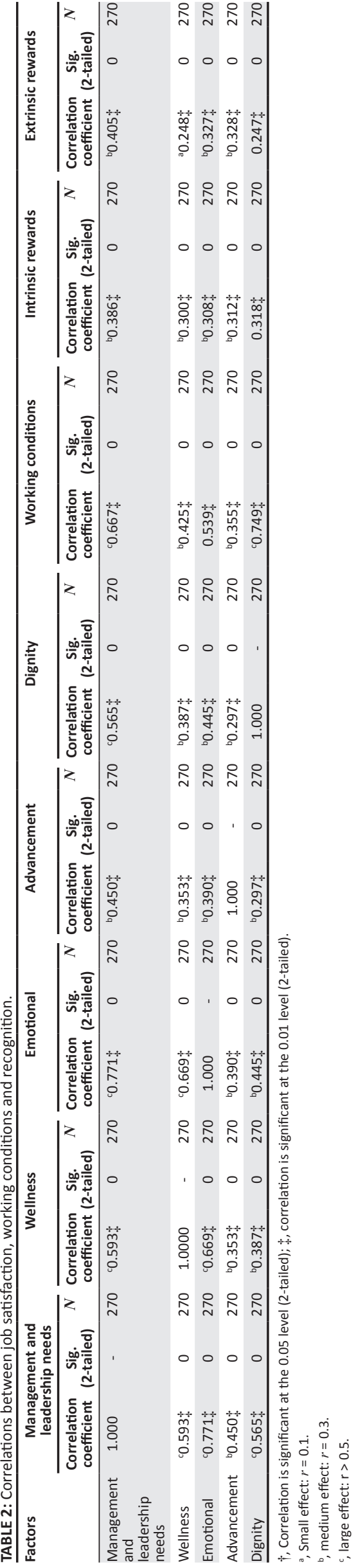

conditions had moderate to large positive correlations with all job satisfaction dimensions, varying between 0.355 (advancement factor) and 0.749 (dignity factor). Intrinsic rewards as well as the extrinsic rewards showed moderate positive correlations with all the dimensions of job satisfaction.

\section{Effect of previous work experience on job satisfaction, working conditions and recognition}

From the results of the $t$-test, it is evident that the $p$-values for all the dimensions of job satisfaction as well as intrinsic rewards and working conditions were 0.05 or higher, indicating that there were no statistically significant differences between the means of respondents with and without previous work experience and job satisfaction, working conditions and intrinsic rewards. The effect sizes for all these dimensions indicated a small effect, varying from 0.02 to 0.22 . However, the $t$-test showed significant differences for the extrinsic rewards factor $(p=0.007)$, where respondents without previous work experience placed more emphasis $(M=4.34)$ on extrinsic rewards than those with work experience $(M=4.05)$. However, the effect was small $(d=0.31)$.

\section{Effect of gender on job satisfaction, working conditions and recognition}

The results of the $t$-test indicated no statistically significant differences between the means of men and women and job satisfaction, working conditions and recognition. The $p$-value for all the dimensions (or factors) measured above 0.2. Furthermore, the effect sizes also indicated a small effect between the dimensions (or factors), varying between 0.00 (working conditions) and 0.15 (advancement).

\section{Effect of race on job satisfaction, working conditions and recognition}

From the results of the ANOVA, it was evident that the $p$-values for four of the dimensions of job satisfaction (management and leadership needs factor, wellness, emotional needs and dignity) as well as working conditions, intrinsic and extrinsic rewards were above 0.05 , indicating no statistically significant differences between the means of different race groups. However, the means of advancement differed statistically significantly $(p=0.006)$, where white respondents $(M=3.75)$ had a lower perception of advancement than black respondents $(M=4.2, d=0.52)$ as well as mixed-race and Indian ( $M$ of both $=4.08, d=0.39)$ respondents.

\section{Effect of field of study on job satisfaction, working conditions and recognition}

The results of the ANOVA indicated no statistically significant differences between the means of the various dimensions for different study fields, as the $p$-values were above 0.05 in all instances. The results of the effect sizes, for all fields of studies and the dimensions of job satisfaction, working conditions and recognition indicated a small to medium effect. 


\section{Discussion}

This research aimed to determine the extent to which perceptions of occupational dimensions influence undergraduate students' perceptions of job satisfaction.

A factor analysis was conducted on the scale items measuring perceptions of job satisfaction, working conditions and recognition. Five factors (management and leadership needs, wellness, emotional needs, advancement and dignity) were extracted and used to measure dimensions of job satisfaction, one factor to measure working conditions and two factors (extrinsic and intrinsic rewards) to measure recognition. Cronbach's coefficient alpha was used to determine the internal reliability of the scales. All values were above the required 0.70, except for the wellness (0.62) and advancement (0.51) factors. This was probably caused by the low number of statements in the factors; however, the mean interitem correlations (wellness 0.303; advancement 0.382) were sufficient (see Clark \& Watson, 1995).

Regarding job satisfaction, the respondents agreed that the various items contained in the five factors (management and leadership needs: mean $=4.58$, wellness: mean $=4.23$, emotional needs: mean $=4.56$, advancement: mean $=3.99$ and dignity: mean $=4.47$ ) were considered important for obtaining job satisfaction. The statements contained in the various dimensions (or factors) also relate to attributes of the job itself, quality co-worker relations, good supervision and the opportunity to grow, which are all considered as the most important factors contributing to job satisfaction in the workplace, as also indicated in the literature review. The advancement factor achieved the lowest mean score (3.99), although still high on the scale varying from 1 (very strongly disagree) to 5 (very strong agree), indicating that advancement opportunities are essential, but are considered less important than all the other dimensions. The management and leadership needs as well as emotional needs were perceived as the most important job satisfaction factors. The results are in line with the findings of the literature review, which indicated that quality co-worker relations (the extent to which an individual is accepted as part of a work unit and the friendliness and support of fellow colleagues) (Millán et al., 2013; Pan, 2015; Smith, 2015; Tang et al., 2014) and good supervision (including fairness, helpfulness, competency and effectiveness) (Fu \& Deshpande, 2014; Pan, 2015; Smith, 2015) are considered important factors for job satisfaction. Furthermore, poor supervisory practices (unfair, biased treatment, failure to listen and respond to employees' concerns and poor communication) (Fu \& Deshpande, 2014; Mathieu et al., 2014; Pan, 2015) and interpersonal conflict (lack of teamwork, unfriendly colleagues) (Pan, 2015; Smith, 2015; Tang et al., 2014) are considered as key factors that diminish job satisfaction.

From the demographic section, four items (previous work experience, gender, race and field of study) were used to measure their effect on the dimensions of job satisfaction, working conditions and recognition. These were tested using t-tests, ANOVAs and effect sizes. The empirical results indicated very few significant differences between the means of the mentioned demographic groups and the dimensions of job satisfaction, working conditions and recognition. The effect sizes also indicated medium to small effects. However, the extrinsic rewards factor differed significantly for respondents with and without previous work experience ( $p=0.007)$, although the effect was small $(d=0.31)$. It indicated that respondents with no work experience on average tend to seek more extrinsic rewards (mean $=4.34$ ) than those with work experience $($ mean $=4.05)$. This finding is consistent with Maslow's theory, which argues that the most basic needs must be met before higher order needs can emerge and become important to the individual (Nel et al., 2014). Extrinsic rewards are also related to the existence needs of Alderfer's ERG theory, which refers to a person's physical and material needs (Werner et al., 2016). Students with no work experience tend to relate recognition in the workplace to extrinsic rewards more than students with work experience, which include performancebased bonuses, salary increases and promotions. Furthermore, the advancement factor differed significantly for different race groups $(p=0.006)$. The results of the effect size showed a medium effect ( $d=0.39$ to 0.52 ), where on average white respondents were less positive (mean = 3.75) about advancement than other races (means larger than 4 ). Therefore, although promotion and advancement opportunities are considered as crucial factors to obtain job satisfaction, black, Indian and mixed-race respondents considered it more important than white respondents.

It is therefore clear from the findings of this research that most demographic variables did not have a significant effect on the dimensions of job satisfaction, working conditions and recognition. This might be because a large number of the respondents (undergraduate students) who participated in this study have not experienced a real working environment yet. Their views of what would satisfy them in their future working environments are only based on their own perceptions thereof.

With regard to the relationships between job satisfaction, working conditions and recognition, significant relationships were found between all the dimensions; the $p$-value measured $<0.001$. Therefore, it can be deduced that all the dimensions were considered important by the students for obtaining job satisfaction in the workplace. This finding is consistent with Herzberg's motivation hygiene theory, which argues that in addition to hygiene factors, motivational factors should be present before satisfaction can be produced and people can be motivated to perform well (Dartey-Baah \& Amoako, 2011; Malik, 2011; Watson, 2012). The items included in the management and leadership needs, advancement, working conditions and extrinsic rewards factors relate to hygiene factors. Items comprising the wellness, emotional needs, dignity and intrinsic rewards factors relate to motivational factors. Furthermore, medium to large positive correlations (between 0.297 and 0.77) were found between almost all the dimensions, except between the extrinsic rewards and the 
wellness (0.248) and dignity factors (0.247), which indicated relatively small correlations. Therefore, extrinsic rewards are considered less important for wellness and dignity in the workplace.

\section{Limitations}

The sample of the study only included undergraduate students. Therefore, not all students included in the sample were exposed to the working environment yet; $57 \%$ of the respondents indicated that they had previous work experience. Therefore, the research was generally based on the perceptions of students' future working environments (regarding the factors affecting job satisfaction) and not based on the actual experience of the working environment itself.

\section{Recommendations}

In the light of the findings of the study, the following recommendations are made. In order to receive a more accurate and reliable response, as well as for the study to apply to a greater context, the study could subsequently be carried out with a larger population and sample, also including other universities. The results of the research study will then be based on a broader spectrum of students' perceptions regarding the factors affecting job satisfaction.

Furthermore, as a result of economic constraints, many students are obliged to undertake some kind of work, either part-time or full-time, to sustain themselves during their undergraduate and postgraduate studies. Working conditions (such as working hours, payment and access to mandatory and voluntary benefits) are often problematic. As students are the future permanent labour force, managers and leaders of a country, it is important that their engagement with the world of work be a positive experience. Therefore, it is recommended that further studies be conducted to measure students' perceptions of job satisfaction in various employment fields, such as nursing, accounting, engineering and service industries (restaurants, transport, etc.). South Africa's young people will in due course shape its future and they have the potential to accelerate growth and encourage development for the country. It is therefore of utmost importance that organisations, in general, and human resource managers, specifically, understand the factors that may have an impact on a country's human capital and may inhibit them to thrive.

\section{Conclusion}

This researched study aimed to determine the relationship between occupational dimensions and undergraduate students' perceptions of the factors affecting job satisfaction. Although the demographic variables (previous work experience, gender, race and field of study) indicated limited significant associations with almost all dimensions of job satisfaction, working conditions and recognition, medium to large positive correlations were found between all the dimensions. Therefore, it can be deduced, on average, that all the dimensions (management and leadership needs, wellness, emotional needs, advancement, dignity, working conditions, intrinsic and extrinsic rewards) are considered important by undergraduate students for obtaining job satisfaction in the workplace.

\section{Acknowledgements Competing interests}

The authors declare that they have no financial or personal relationships that may have inappropriately influenced them in writing this article.

\section{Authors' contributions}

R.V.D.S. conducted the literature review as well as the empirical research. D.B. acted as the supervisor of the research project, assisted with the literature review and the empirical research and wrote up the article. S.E. conducted the statistical analysis and reviewed the article.

\section{References}

Abu-Saad, I., \& Isralowitz, R. E. (1997). Gender as a determinant of work values among university students in Israel. The Journal of Social Psychology, 137(6), 749-763. https://doi.org/10.1080/00224549709595496

Alam, M. M., \& Mohammad, J. F. (2010). Level of job satisfaction and intent to leave among Malaysian nurses. Business Intelligence Journal, 3(1), 123-137.

Al-Zoubi, M. T. (2012). Generating benchmarking indicators for employee job satisfaction. Total Quality Management \& Business Excellence, 23(1), 27-44. https://doi.org/10.1080/14783363.2011.637780

Aziri, B. (2011). Job satisfaction: A literature review. Management Research and Practice, 3(4), 77-86.

Babbie, E., \& Mouton, J. (2009). The practice of social research. Oxford: Oxford University Press.

Chang, W. Y., Ma, J. C., Chiu, H. T., Lin, K. C., \& Lee, P. H. (2009). Job satisfaction and perceptions of quality patient care, collaboration and teamwork in acute hospitals. Journal of Advanced Nursing, 65(9), 1946-1955. https://doi.org/10.1111/j.13652648.2009.05085.x

Chatzoglou, P. D., Vraimaki, E., Komsiou, E., Polychrou, E., \& Diamantidis, A. D. (2011, July). Factors affecting accountants' job satisfaction and turnover intentions: A structural equation model. Paper presented at the 8th International Conference on Enterprise Systems, Accounting and Logistics, Thassos Island, Greece.

Chowdhary, B. (2013). Job satisfaction among bank employees: An analysis of the contributing variables towards job satisfaction. International Journal of Technology Enhancements and Emerging Engineering Research, 2(8), 11-20.

Clark, L. A., \& Watson, D. (1995). Constructing validity: Basic issues in objective scale development. Psychological Assessment, 7(3), 309-319. https://doi.org/10.1037/ 1040-3590.7.3.309

Creswell, J. W. (2009). Research design: Qualitative, quantitative, and mixed methods approaches (4th edn.). Los Angeles, CA: Sage.

Cohen, J. (1988). Statistical power analysis for the behavioral sciences (2nd edn.) Hillsdale, NJ: Erlbaum.

Dartey-Baah, K., \& Amoako, G. K. (2011). Application of Frederick Herzberg's twofactor theory in assessing and understanding employee motivation at work: A Ghanaian perspective. European Journal of Business and Management, 3(9), 1-8.

De Jager, C. J. (2015). Measuring the job satisfaction of young engineers at Eskom power stations (Unpublished master's dissertation). North-West University, Potchefstroom.

Dul, J., Ceylan, C., \& Jaspers, F. (2011). Knowledge workers' creativity and the role of the physical work environment. Human Resource Management, 50(6), 715-734. https://doi.org/10.1002/hrm.20454

Elfering, A., Odoni, M., \& Meier, L. L. (2016). Today's work experience: Precursors of both how I feel and how I think about my job? Revista de Psicología del Trabajo de las Organizaciones, 32(1), 11-16. https://doi.org/10.1016/j.rpto.2015.11.001

Field, A. (2005). Discovering statistics using SPSS (2nd edn.). London: Sage.

Fu, W., \& Deshpande, S. P. (2014). The impact of caring climate, job satisfaction, and organizational commitment on job performance of employees in a China's insurance company. Journal of Business Ethics, 124(2), 339-349. https://doi. org/10.1007/s10551-013-1876-y

Gazioglu, S., \& Tansel, A. (2006). Job satisfaction in Britain: Individual and job related factors. Applied Economics, 38(10), 1163-1171. https://doi.org/10.1080/ 00036840500392987 
Goetz, K., Campbell, S. M., Broge, B., Dörfer, C. E., Brodowski, M., \& Szecsenyi, J. (2012). The impact of intrinsic and extrinsic factors on the job satisfaction of dentists. Community Dentistry and Oral Epidemiology, 40(5), 474-480. https:// dentists. Community Dentistry and Oral Epid

Grobler, P. A., Wärnich, S., Carrell, M. R., Elbert, N. F., \& Hatfield, R. D. (2011). Human resource management in South Africa (4th edn.). London: Cengage Learning EMEA.

Hanna, B., Kee, K. F., \& Robertson, B. W. (2017). Positive impacts of social media at work: Job satisfaction, job calling, and Facebook use among co-workers. SHS Web of Conferences, 33, 1-9. https://doi.org/10.1051/shsconf/20173300012

Hartman, N. N., Rutherford, B. N., Feinberg, R., \& Anderson, J. G. (2014). Antecedents of mentoring: Do multi-faceted job satisfaction and affective organizational commitment matter? Journal of Business Research, 67(9), 2039-2044. https:// doi.org/10.1016/j.jbusres.2013.10.006

Hayes, B., Bonner, A. N. N., \& Pryor, J. (2010). Factors contributing to nurse job satisfaction in the acute hospital setting: A review of recent literature. Journal of Nursing Management, 18(7), 804-814. https://doi.org/10.1111/j.1365-2834.2010.01131.x

Hersch, J., \& Xiao, J. (2016). Sex, race, and job satisfaction among highly educated workers. Southern Economic Journal, 38(1), 1-24. https://doi.org/10.1002/ soej.12133

Hoppe, A., Fujishiro, K., \& Heaney, C. A. (2014). Workplace racial/ethnic similarity, job satisfaction, and lumbar back health among warehouse workers: Asymmetric reactions across racial/ethnic groups. Journal of Organizational Behavior, 35(2), 172-193. https://doi.org/10.1002/job.1860

Ingram, T. (2015). Employee compensation and job satisfaction in health care organizations in Poland. In J. Vopava, V. Douda, R. Kratochvil, \& M. Konecki (Eds.) Proceedings of MAC-EMM 2015 in Prague (pp. 213-220). Prague: MAC Prague Consulting.

Jiang, L., \& Alexakis, G. (2017). Comparing students' and managers' perceptions of essential entry-level management competencies in the hospitality industry: An empirical study. Journal of Hospitality, Leisure, Sport \& Tourism Education, 20(1) 32-46. https://doi.org/10.1016/j.jhlste.2017.01.001

Jiang, Z., Xiao, Q., Qi, H., \& Xiao, L. (2009). Total reward strategy: A human resources management strategy going with the trend of the times. International Journal of management strategy going with the trend of the times. I/ternational Journal of
Business and Management, 4(11), 177-183. https://doi.org/10.5539/ijbm. v4n11p177

Josiam, B. M., Crutsinger, C., Reynolds, J. S., Dotter, T. V., Thozhur, S., Baum, T., \& Devine, F. G. (2009). An empirical study of the work attitudes of Generation $Y$ college students in the USA: The case of hospitality and merchandising college students in the USA: The case of hospitality and
undergraduate majors. Journal of Services Research, 9(1), 5-25.

Judge, T. A., Weiss, H. M., Kammeyer-Mueller, J. D., \& Hulin, C. L. (2017). Job attitudes, job satisfaction, and job affect: A century of continuity and of change. Journal of Applied Psychology, 102(3), 356-374. https://doi.org/10.1037/apl0000181

Kardam, B. L., \& Rangnekar, S. (2012). Job satisfaction: Investigating the role of experience \& education. Journal of Arts, Science \& Commerce, 4(1), 16-22.

Koh, C., Shen, W., \& Lee, T. (2016). Black-white mean differences in job satisfaction: A meta-analysis. Journal of Vocational Behavior, 94, 131-143. https://doi. org/10.1016/j.jvb.2016.02.009

Levin, I., \& Stokes, J. P. (1989). Dispositional approach to job satisfaction: Role of negative affectivity. Journal of Applied Psychology, 74(5), 752-757. https://do org/10.1037/0021-9010.74.5.752

Liu, G. (2017). Job design, training effect and job satisfaction: Evidence from work placement at audit firms. SHS Web of Conferences, 34, 1-7. https://doi. org/10.1051/shsconf/73406002

Lumley, E. J., Coetzee, M., Tladinyane, R., \& Ferreira, N. (2011). Exploring the job satisfaction and organisational commitment of employees in the information technology environment. Southern African Business Review, 15(1), 100-118.

Malik, M. E., Nawab, S., Naeem, B., \& Danish, R. Q. (2010). Job satisfaction and organizational commitment of university teachers in public sector of Pakistan. International Journal of Business and Management, 5(6), 17-26. https://doi. org/10.5539/ijbm.v5n6p17

Malik, N. (2011). Study on job satisfaction factors of faculty members at university of Balochistan. International Journal of Academic Research, 3(1), 267-272.

Mathieu, C., Neumann, C. S., Hare, R. D., \& Babiak, P. (2014). A dark side of leadership Corporate psychopathy and its influence on employee well-being and job satisfaction. Personality and Individual Differences, 59, 83-88. https://doi. org/10.1016/j.paid.2013.11.010

Meyer, M., Bushney, M., Katz, M., Knoke, G., Ludike, J., Meyer, M., ... Wofson, R. (2012). Managing human resource development: A strategic learning approach (4th edn.). Cape Town: LexisNexis.

Milkovich, G. T., Newman, J. M., \& Gerhart, B. (2011). Compensation (10th edn.). New York: McGraw-Hill.

Millán, J. M., Hessels, J., Thurik, R., \& Aguado, R. (2013). Determinants of job satisfaction: A European comparison of self-employed and paid employees. Small Business Economics, 40(3), 651-670. https://doi.org/10.1007/s11187-011-9380-1

Moyes, G. D., Shao, L. P., \& Newsome, M. (2008). Comparative analysis of employee job satisfaction in the accounting profession. Journal of Business \& Economics Research, 6(2), 50-80.
Moynihan, D. P., \& Pandey, S. K. (2007). Finding workable levers over work motivation comparing job satisfaction job involvement, and organizational commitment. Administration\&Society,39(7),803-832.https://doi.org/10.1177/0095399707305546

Nel, P., Werner, A., Botha, C., Du Plessis, A., Mey, M., Ngalo, O., ... Van Hoek, L. (2014). Human resource management (9th edn.). Cape Town: Oxford University Press Southern Africa.

Noe, R. A., Hollenbeck, J. R., Gerhart, B., \& Wright, P. M. (2012). Human resource management: Gaining a competitive advantage. New York: McGraw-Hill.

O'Leary, Z. (2013). The essential guide to doing your research project. London: Sage.

Pan, F. C. (2015). Practical application of importance-performance analysis in determining critical job satisfaction factors of a tourist hotel. Tourism Management, 46, 84-91. https://doi.org/10.1016/j.tourman.2014.06.004

Proudfoot, D., \& Lind, E. A. (2015). Fairness heuristic theory, the uncertainty management model, and fairness at work. In R. S. Cropanzano \& M. L. Ambrose (Eds.), The Oxford handbook of justice in the workplace (pp. 371-385). Cape Town: Oxford University Press. https://doi.org/10.1093/oxfordhb/9780199981410. Oxford
013.17

Resick, C. J., Baltes, B. B., \& Shantz, C. W. (2007). Person-organization fit and workrelated attitudes and decisions: Examining interactive effects with job fit and conscientiousness. Journal of Applied Psychology, 92(5), 1446-1455. https://doi. conscientiousness. Journal of Applied
$\mathrm{org} / 10.1037 / 0021-9010.92 .5 .1446$

Ritchie, J., Lewis, J., Nicholls, C. M., \& Ormston, R. (Eds.). (2013). Qualitative research practice: A guide for social science students and researchers. London: Sage.

Robbins, S. P., Judge, T. A., Odendaal, A., \& Roodt, G. (2009). Organisational behaviour: Global and South African perspectives (2nd edn.). Cape Town: Pearson Education South Africa.

Rothman, S. (2001). Sense of coherence, locus of control, self-efficacy and job satisfaction. South African Journal for Economic and Management Sciences, 4(1) 40-64.

Sabharwal, M., \& Corley, E. A. (2009). Faculty job satisfaction across gender and discipline. The Social Science Journal, 46(3), 539-556. https://doi.org/10.1016/j. soscij.2009.04.015

Sarantakos, S. (2013). Social research (4th edn.). New York: Palgrave Macmillan.

Shin, J. C., \& Jung, J. (2014). Academics job satisfaction and job stress across countries in the changing academic environments. Higher Education, 67(5), 603-620. https://doi.org/10.1007/s10734-013-9668-y

Skaalvik, E. M., \& Skaalvik, S. (2014). Teacher self-efficacy and perceived autonomy: Relations with teacher engagement, job satisfaction, and emotional exhaustion Psychological Reports, 114(1), 68-77. https://doi.org/10.2466/14.02. PRO.114k14w0

Smith, J. C. (2015). Pay growth, fairness, and job satisfaction: Implications for nominal and real wage rigidity. The Scandinavian Journal of Economics, 117(3), 852-877. https://doi.org/10.1111/sjoe.12091

Sousa, V. D., Driessnack, M., \& Mendes, I. A. C. (2007). An overview of research designs relevant to nursing: Part 1: Quantitative research designs. Revista LatinoAmericana de Enfermagem, 15(3), 502-507. https://doi.org/10.1590/S010411692007000300022

Stoermer, S., Hitotsuyanagi-Hansel, A., \& Froese, F. J. (2017). Racial harassment and job satisfaction in South Africa: The moderating effects of career orientations and managerial rank. The International Journal of Human Resource Management 23(1), 1-20. https://doi.org/10.1080/09585192.2016.1278254

Tan, T. H., \& Waheed, A. (2011). Herzberg's motivation-hygiene theory and job satisfaction in the Malaysian retail sector: The mediating effect of love of money. satisfaction in the Malaysian retail sector: The mediatin
Asian Academy of Management Journal, 16(1), 73-94.

Tang, S. W., Siu, O. L., \& Cheung, F. (2014). A study of work-family enrichment among Chinese employees: The mediating role between work support and job
satisfaction. Applied Psychology, 63(1), 130-150. https://doi.org/10.1111/j.1464satisfaction. Applied

Valentine, S., Godkin, L., Fleischman, G. M., \& Kidwell, R. (2011). Corporate ethical values, group creativity, job satisfaction and turnover intention: The impact of work context on work response. Journal of Business Ethics, 98(3), 353-372. work context on work response. Journal
https://doi.org/10.1007/s10551-010-0554-6

Van der Schyff, R. (2016). The relationship between undergraduate students perceptions of occupational dimensions and undergraduate students' perceptions of job satisfaction. Mini-dissertation - Honours. Potchefstroom: North-West University.

Watson, T. J. (2012). Sociology, work and organisation (6th edn.). New York: Routledge.

Werner, A., Bagraim, J., Cunningham, P., Potgieter, T., \& Viedge, C. (2016). Organisational behaviour: A contemporary South African perspective (4th edn.). Pretoria: Van Schaik.

West, C. P., Dyrbye, L. N., Rabatin, J. T., Call, T. G., Davidson, J. H., Multari, A., .. Shanafelt, T. D. (2014). Intervention to promote physician well-being, job satisfaction, and professionalism: A randomized clinical trial. JAMA Interna Medicine, 174(4), 527-533. https://doi.org/10.1001/jamainternmed.2013.14387

Wu, L., \& Norman, I. J. (2006). An investigation of job satisfaction, organisational commitment and role conflict and ambiguity in a sample of Chinese undergraduate nursing students. Nurse Education Today, 26(4), 304-314. https://doi org/10.1016/j.nedt.2005.10.011 